\title{
Towards Building a Platform for e-Social On-demand Learning and Development
}

\author{
Thu Thuy Trieu and Ngo D. Nga
}

\begin{abstract}
Today, there are different models of e-learning in which people share their professional knowledge or study to develop their comprehensive skills via the Internet. However, existing e-learning platforms somehow support passive learning in the sense that lecturers publishes learning resources and attenders access to join the courses. Such model is more appropriate for long and completed courses but hard to be applied for quick and active learning. We envisage that building a novel e-learning model of the e-society where learners can push their queries and match with the most suitable teachers, so that an active channel for teaching and learning can be built. This paper aims at developing a proof-of-concept system for e-social on-demand learning and development to meet such demand with prominent features without refuting other existing systems. We call it NetCloudTab system.
\end{abstract}

Index Terms-E-learning, e-social, NetCloudTab, on-demand learning and development.

\section{INTRODUCTION}

According to the statistics of a report on Internetlivestats [1].

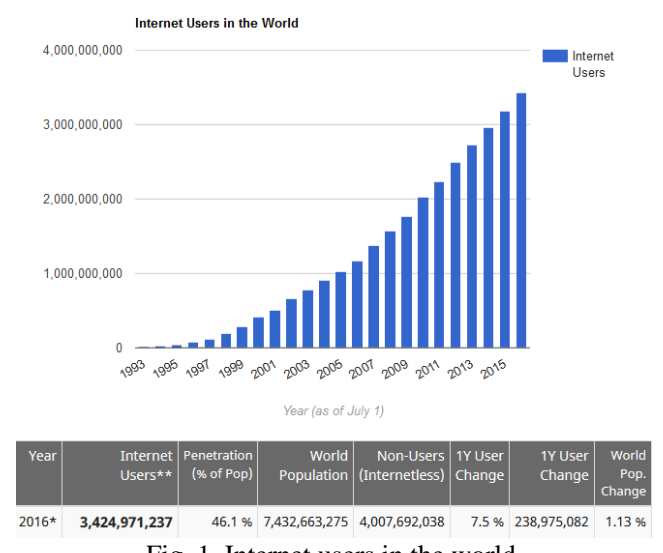

Fig. 1. Internet users in the world.

The number of Internet users to 2016 will reach $45 \%$ of the world population (Fig. 1). We are living in an electronic society of 3 billion people with different social networks and different online applications. How come all citizens of global network regardless of different age, income or wealth can have equal opportunities in learning, sharing and developing themselves with the barrier of geography and space?

The other report of Internetlivestats [2] showed that

Manuscript received August 22, 2016; revised January 10, 2017

Thu Thuy Trieu is with Institute of Information Technology (IOIT), Vietnam Academy of Science and Technology, Vietnam (e-mail: thuytrieu@ioit.ac.vn).

Ngo D. Nga is with Foundation Department of International School, Vietnam National University, Hanoi, Vietnam.
Google now processes over 40,000 search queries every second on average, which translates to over 3.5 billion searches per day and 1.2 trillion searches per year worldwide. It seems that people are effort-fully looking for the answers by search engines but search engines can give only related information. Questioners no way have to become analysts of comprehensive information. This is the weakness of search engines when questioners do not have time to synthesize the related information or they are not qualified enough to verify the right or wrong of multifaceted information. Is there a way to help user get instant answers for instant questions from a reliable source that the person has experienced analyzing and synthesizing the related information?

This paper aims at building a platform for e-social learning and development to meet such needs without refuting the existing system. It is called NetCloudTab system.

\section{RELATED WORK}

Our e-society currently exists many systems and applications to support e-learning and share intellectual knowledge and online co-ordination [3].

The Table I below indicates the differences among some related systems MOOCs (Edx, Coursera ...) [4], Gotitapp [5], LinkedIn [6], Freelancer [7], and NetCloudTab.

Freelance can meet the need of ordering and purchasing a tangible product such as handicraft, arts, a designed product, or programming... However, this is not an online training system and not a place for people to express the knowledge and have the connection.

Today it is easy to find an online learning system with various sites giving courses for instance $\mathrm{EdX}$, Coursera, Udacity, Lynda....Nevertheless, these sites only standstill at offering available courses which learners can register to participate in [8].

With LinkedIn, the connections are reliable and professional. By nature, it is completely a storage place of CVs with various connections. This is an ideal site designed for labor market, in a way that headhunters look for suitable positions and co-operations.

With Gotitapp, it is more interesting that the concept of on-demand is firstly seen in e-learning but unfortunately this system only halts at some natural science subjects for target students and the language is basically in English.

With NetCloudTab, the users can have answers for all kinds of questions in many different fields.

\section{DESCRIBING THE SYSTEM}

The system is considered as a platform for personal 
learning and development in an electronic society. Thanks to this system, people are not only learning to get a certificate or gain professional knowledge but also using their own knowledge to trade-off Knowledge score. Instead of spending too much time searching, user can join Knowledge marketplace to ask or request directly someone suitable who has the answer in the expected conditions.

TABLE I: COMPARING SOME RELATED SYSTEMS

\begin{tabular}{|c|c|c|c|c|c|}
\hline & \multicolumn{5}{|c|}{ 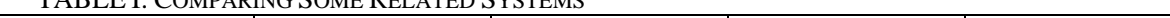 } \\
\hline & $\begin{array}{c}\text { MOOC }(\mathbf{E d x}, \\
\text { Coursera,.. })\end{array}$ & Gotitapp & LinkedIn & Freelancer & NetCloudTab \\
\hline Tangible products & & & & $\mathrm{v}$ & $\mathrm{v}$ \\
\hline E-learning & $\mathrm{v}$ & $\mathrm{v}$ & & & $\mathrm{v}$ \\
\hline On-demand & & $\mathrm{v}$ & & $\mathrm{v}$ & $\mathrm{v}$ \\
\hline Communication Online & & $\mathrm{v}$ & $\mathrm{v}$ & $\mathrm{v}$ & $\mathrm{v}$ \\
\hline Express yourself & & & $\mathrm{v}$ & & $\mathrm{v}$ \\
\hline Connect communities & & & $\mathrm{v}$ & & $\mathrm{v}$ \\
\hline Unlimited topics & $\mathrm{v}$ & & & $\mathrm{v}$ & $\mathrm{v}$ \\
\hline Instant requests & & & & & $\mathrm{V}$ \\
\hline
\end{tabular}

\section{A. General about Knowledge Marketplace}

There are two main actors to join actions in the Knowledge marketplace. They are Clouder and Taber

- Clouder

Express themselves: CV, avatar, general ranking

Offer knowledgeable topics: knowledge zone, method, price, time, ranking, comment, area, language

Open booking time

Choose suitable instant request which can be resolved

- Taber

Book suitable Clouder's open time

Broadcast request/question (instant problem) with conditions: waiting time, knowledge zones, respond method, areas ...

Choose suitable Clouder to hide to resolve the problem

Any user can be Taber or Clouder (under 18 years old, a protector is needed). A user can trade their knowledge in the "knowledge marketplace" as a Clouder or Taber. In this market, Knowledge score is used instead of money. Knowledge is an intangible asset so the concept of trading here does not necessarily mean that after trading, Clouder will lose that knowledge but in a sense that Clouder spend their time and effort to gain the Knowledge score.

Fig. 2 indicates some attributes of a Clouder.

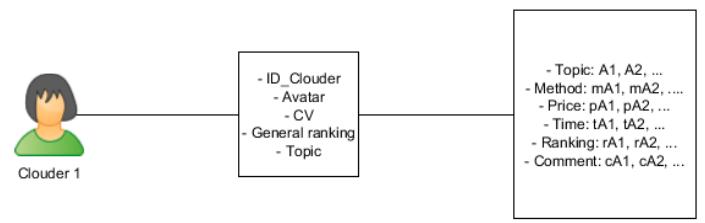

Fig. 2. Some attributes of a Clouder.

Thus, this system is not refute the above related system because a Clouder wants to have knowledge score as highly as possible while the Clouder needs as much as possible the way to accumulate knowledge.

\section{B. Trading Offered Knowledge}

Any Taber can use the function "Search topic" to see the list of suitable Clouders who offer the knowledge that Taber is looking for. Fig. 3 shows the diagram of a user case for trading knowledge function offered by Clouder.

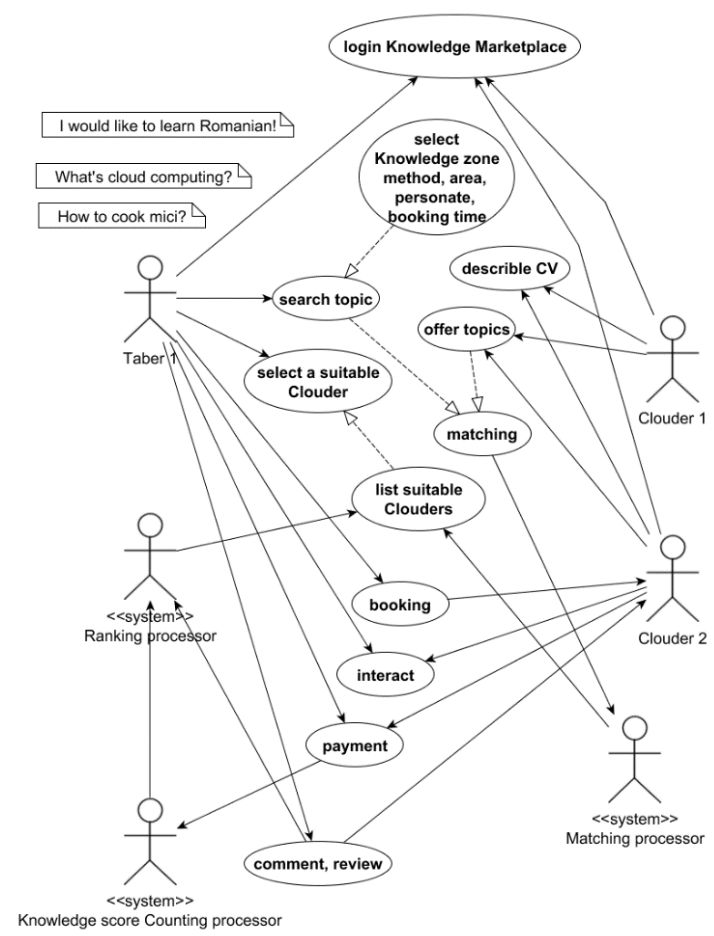

Fig. 3. Trading offered knowledge.

\section{Trading On-demand Knowledge}

Beside "search topic" function which is similar to normal MOOCs, the system route to serve personalized, any Taber can broadcast request which suits the Clouder with conditions: waiting time, knowledge zones, respond method, area, language. All requests and responses are sent instantly, and posted online immediately on the Knowledge Market. The system matches and rank the Clouder based on topics (and the knowledge zone), open time, response method, comment, price, ranking, score, area, language (Fig. 4). 


\section{SPeCial FeAtures}

These special features of this system can help users to learn more easily and achieve their personal development by questioning without hesitation via search topics to trade offered knowledge or push questions to trade on-demand knowledge, selecting the right answer in the shortest time. These features can be very advantageous in urgent situations.

\section{A. Ensuring the Privacy of Personal Information}

Most of online services identify users with an account of identity before starting to use their service. Recently, there is a tendency that service providers require users to connect with social networks. In an extreme sense, some services do not allow the use of email for identification but only the use of a social network account of Facebook or Twitter Previously service providers only gather information of users by their services. Now they can gather information of users by social networks with a sophisticated reason of upgrading their services. However, when using services of provider A, information of user $\mathrm{X}$ can be revealed to provider $\mathrm{B}$ and users $\mathrm{Y}$ or $\mathrm{Z}$ can find $\mathrm{X}$ 's information somewhere else. This is especially important in e-learning process. Many people hesitate to ask questions because they are afraid of being underestimated. Some people after mastering a knowledge now do not want others to know what they used to ask in the past. Being ashamed is a barrier for development. Citizens living in an electronic society spend too much time searching but still cannot get the most accurate information.

NetCloudTab can reconcile benefits between the two service providers and achieve the secured information of users. The system allows users to select their identity before an action.

There are three types of identity:

- Public real name

- Public personate

\section{- Incognito}

Each person has only one Public real name to connect with real account from email or social network that is activated. All their knowledge scores are added or deducted based on this identity. The second identity, Public personate, each person can have many identity names. If compared with Public real name as static IP address, Public personate can be considered as private/dynamic IP address which is given automatically and randomly. The third type, Incognito, users can completely hide their information even with the administration system, something that the knights usually do. In the third case, Incognito Clouder cannot be added their knowledge scores. When users act as Taber, users are not allowed to use Incognito identity to ensure the connection between public real name and public personate.

\section{B. On-demand Online Interaction}

The concept of on-demand here is not only the request of Taber about a topic but also the condition of Taber about the time of response, a position of request broadcast.

This feature permits Taber to use in urgent situation with default conditions such as location for request broadcast which is the positioning of Taber. Hence, Clouder who is near Taber will receive the request the earliest. The assistance or spreading information in urgent situation can be faster and more in time. In this case, other indicators such as name, area are configured by Taber.

\section{Social Equality, Knowledge Sharing and Connecting}

Everyone can have a chance to become Clouder when they have knowledge to sell and switch to Taber when in need of buying knowledge. From the young to elderly people, from workers to professors, from the homeless to the billionaires, from someone from remote African deserts to the ones living in the Himalayas or the North Pole, everyone has their own knowledge. Everyone can participate to share the knowledge they own.

The system can overcome the barriers of tuition fee because everyone can sell before they buy, then Taber may not need real money.

Fig. 5 describes an imitative interface of homepage for the system. Taber can easily look for Clouder which is similar to looking for an application in Application store with convenient rating classified by items, knowledge scores, booking time or even reputation in the real world.

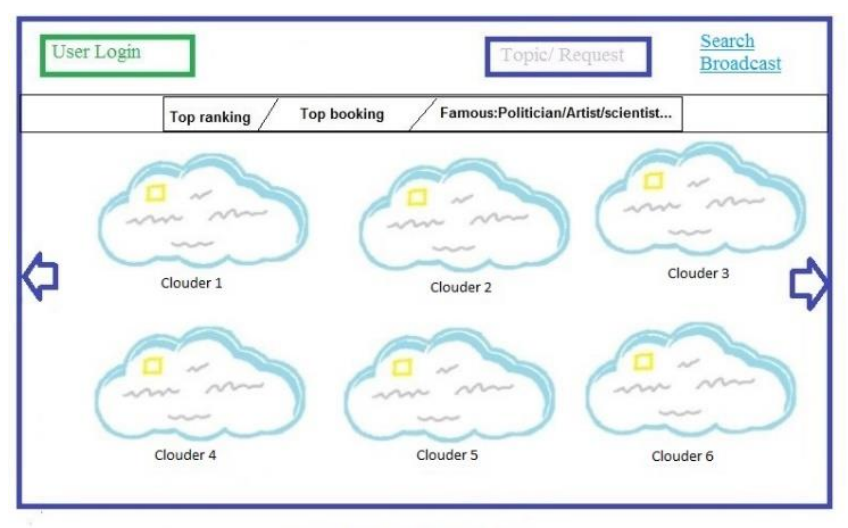

Knowledge Marketplace

Fig. 5. An imitative interface of homepage for Taber portal.

\section{CONCLUSIONS}

This paper proposes an overall solution for e-social learning and developing system called the NetCloudTab system. This system focuses on more personalized and more real time interaction than other existing systems. In addition, the system brings in opportunities of learning and developing for all users of Internet. However, this paper just presents the concept and gives an overview analysis. In the time coming, we will develop the product and have an assessment of testing on the real system. Aiming at users globally, there will be mathematical problems of big data application to be taken into consideration.

\section{ACKNOWLEDGMENT}

We would like to thank Professor Dana Petcu for her expert advice and encouragement in this paper.

\section{REFERENCES}

$\begin{array}{lll}\text { Internet-users. } & \text { Anline]. } & \text { Available: } \\ \text { http://www.internetlivestats.com/internet-users/ } & \text { Anline]. } & \text { Available: } \\ \text { Internetlivestats. } & \text { [Online-statistics/ } & \end{array}$


[3] J. Hart, Social Learning Handbook 2014, Centre for Learning \& Performance Technologies, 2014.

[4] Edx. [Online]. Available: https://www.edx.org/

[5] Otitapp. [Online]. Available: http://www.gotitapp.co/

[6] Linkedin. [Online]. Available: https://www.linkedin.com/

[7] Freelancer. [Online]. Available: https://www.freelancer.com

[8] S. Hatzipanagos, "What do MOOCs contribute to the debate on learning design of online courses?" Open Education, Design Patterns for Open Online Teaching and Learning.

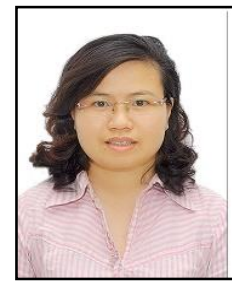

Thu Thuy Trieu is researcher in Institute of Information Technology (IOIT), Vietnam Academy of Science and Technology. Some recent projects that she has joined are: "Grid and cloud computing applications for the availability of the tsunam propagation scenario may occur in the East Sea in order to serve warning 2012-2013", "Building Stratuslab IaaS cloud in IOIT 2011". Thu Thuy Trieu graduated the MSc from Information Technology Program of University of Engineering and Technology, Vietnam National University in 2011. She has been pursuing her $\mathrm{PhD}$ process in professor Dana Petcu's Group, West University of Timisoara, Romania since 2015. Her research interests is about "Cloud-based data-intensive applications".

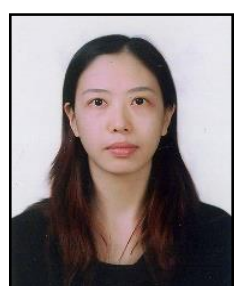

Ngo Dung Nga received the M.A degree of international studies from Graduate School of International Studies, Chung Ang University in Seoul, Korea in 2002. She is at present working as a lecturer at Foundation Department of International School, Vietnam National University, Hanoi. She teaches courses of English for academic purposes, English for specific purposes. Her research interests include teaching methodology, educational technology, using technology to enhance learning, and globalization. 